\title{
Endovascular management of dural fistulas into the cavernous sinus. A systematic review
}

\author{
Luis Rafael Moscote-Salazar ${ }^{1}$, Marco Zenteno ${ }^{2}$, Jorge A Santos- \\ Franco $^{3}$, Nancy Carolina Duarte-Valdivieso ${ }^{4}$, Hernando Raphael \\ Alvis-Miranda ${ }^{1}$, Angel Lee ${ }^{5}$ \\ ${ }^{1}$ Universidad de Cartagena, Colombia \\ ${ }^{2}$ Instituto Nacional de Neurologia y Neurocirugía "Manuel Velasco Suarez", Mexico \\ ${ }^{3}$ IMSS “La Raza” Mexico D.F, Mexico \\ ${ }^{4}$ Chang Gung Memorial Hospital, Linkou, Taiwan \\ ${ }^{5}$ Hospital Angeles del Pedregal, Mexico
}

\begin{abstract}
Background: Dural fistula to the cavernous sinus (DFCS) is an infrequent pathology that consists in the anomalous communication between the meningeal branches of the internal carotid artery (ICA) and/or the external carotid artery (ECA) and the cavernous sinus.

Aim: To perform a systematic review to evaluate clinical and imaging findings in DFCS, and current indications for treatment.

Methods: A literature search was performed in several medical databases using the keywords "intracranial dural fistula", "carotid-cavernous fistula", "endovascular treatment", associated with "outcome"; resulting articles were assessed by considering factors such as: number of patients treated, type of material used, complications, and type of image technique used for diagnosis.

Results: 33 articles were selected, yielding: clinical and imaging: The symptoms are basically related to the type of venous drainage
\end{abstract}

of the fistula. The combination of ocular symptoms and tinnitus is highly suggestive of DFCS. Ocular symptoms are found in $80-97 \%$ of patients, while the tinnitus is present in up to $50 \%$ of cases. The imaging method for initial assessment of the DFCS is the magnetic resonance imaging. Digital subtraction angiography is the method of choice to determine adequately the precise angioarchitecture of the injury and its drainage. This data is of vital importance in future decision making. Treatment: Currently are considered as indications for the management of DFCS: 1) rapidly progressive deterioration of visual function, 2) angiographic evidence of abnormal cortical venous drainage, 3 ) the hypoxic consequences in retina and optic nerve, and 4) ischemic keratitis; the most suitable materials for embolization of the DFCS are CA and PAP.

Conclusion: DFCS stills being an uncommon cerebrovascular condition, with good outcomes from endovascular treatment. 
Key words: Dural fistula; carotidcavernous fistulas; N-butil-cyanoacrylate; cavernous sinus.

\section{Introduction}

Intracranial arteriovenous fistulae are of two main types: carotid-cavernous fistulas (CCF) and dural arteriovenous fistulas. CCF is an infrequent pathology that consists in the anomalous communication between the meningeal branches of the internal carotid artery (ICA) and/or the external carotid artery (ECA) and the cavernous sinus. These belong to the indirect CCF. Unlike direct CCF which are frequently evocated by trauma, (1-5) indirect CCF more commonly occur spontaneously, being rare the traumatic etiology. (5, 6) Clinical manifestations generally follow a less severe course than direct CCF, being the ophthalmological symptoms and the presence of superior drainage, the most relevant data, mainly for provide an adequate therapeutic approach. Currently the preferred management is the endovascular. In this article we present a systematic review about endovascular management of dural fistulas into the cavernous sinus.

\section{Methods}

A literature search was performed in several medical databases including PubMed, EMBASE, Scopus, and Google Scholar; without restrictions or filters with regard to language or year of publication; showing a total of 33 results using the keywords "intracranial dural fistula", "carotid-cavernous fistula", "endovascular treatment", associated with "outcome". Emphasis was given to the angiographic, imaging and hemodynamic characteristics found usually in dural fistulas to the cavernous sinus (DFCS); the resulting articles were assessed by considering factors such as: number of patients treated, type of material used, complications, and type of image technique used for diagnosis.

\section{Etiology}

Indirect CCF occurs typically and spontaneously in postmenopausal women, although they can occur also in other age groups as consequence of pregnancy, sinusitis or cavernous sinus thrombosis. (5-8). There is not a universal and convenient explanation regard its genesis, however, since Houser et al demonstrated that thrombosis of the lateral and sigmoid sinus precede the formation of dural fistulas, many authors implied the thrombosis of the cavernous sinus as the natural precursor of the DFCS, pushing away the theory proposed by Newton and Hoyt, who pointed out as cause, the microtraumatisms over the delicate vessels of the carotid siphon (7).

Meyers et al (5), reported their 15 years' experience in the management of 135 consecutive patients with diagnosis of DFCS, being none of traumatic etiology. Therefore, the frank traumatic etiology of the DFCS is extremely rare. Berenstein et al (9) in 1986, reported 11 cases of arteriovenous fistulas, and mention one of DFCS of traumatic origin. Keltner et al (10) in 1987, described the case of traumatic indirect CCF within a total of 12 cases of CCF. Higashida et al (11) in an extensive review of 213 traumatic CCF published in 1989, found 7 cases of indirect fistula to the cavernous sinus. Jacobson et al 
DOI: 10.2478/romneu-2014-0015

(6), in 1996 reported two additional cases of traumatic indirect CCF.

Notably, Jacobson and colleagues conclude that the recognition of traumatic origin allow an adequate choice of route and material to be used, we do not think that the traumatic history is a planning guide for management, we believe the choice of route and the material will be governed by the amount and type of tributaries that have the fistula, and venous drainage pattern, considerations that go far beyond agreement cited by other authors $(6,7$, $10,12)$.

\section{Clinical and imaging findings}

\section{Clinical findings}

The symptoms are basically related to the type of venous drainage of the fistula, therefore: 1) anterior drainage into the superior ophthalmic vein originate ophthalmic symptoms, for example, exophthalmos and chemosis; 2) posteroinferior drainage into the petrosal sinus, basilar plexus and pterygoid plexus will produce murmurs, and deficit of some cranial nerves; 3) subsequent drainage into the superior petrosal sinus originates murmur; 4) cortical reflux into the sphenoparietal sinus and upper middle cerebral vein may cause infarction and hemorrhage; and 5) deep drainage into the deep middle cerebral vein and the uncal vein can trigger hemorrhages (13).

These symptoms affecting intracranial and extracranial structures can be grouped into four patterns (14): a) orbital including chemosis, proptosis, eyelid edema and periorbital pain, b) cavernous with ptosis, diplopia, anisocoria and ophthalmoplegia, c) ocular with decreased visual acuity or increased intraocular pressure ( $>20 \mathrm{mmHg}$ or interocular difference greater than $5 \mathrm{mmHg}$ ), severe eye pain, glaucoma, and retinal hemorrhage, and d) cerebral, including cerebral venous congestion in the basal ganglia, brain stem or cerebellum promoting presence of epilepsy and hemorrhage.

The combination of ocular symptoms and tinnitus is highly suggestive of DFCS. Ocular symptoms are found in $80-97 \%$ of patients, while the tinnitus is present in up to $50 \%$ of cases. These symptoms are usually less dramatic than direct CCF, and rarely are lifethreatening. The flow of DFCS is usually much lower than the direct CCF, being the most important reason to present a less aggressive clinical spectrum, however there are reports of significant morbidity such as blindness and stroke $(15,16)$. About 30 to $40 \%$ cases of indirect CCF present cerebral hemorrhage due to the rupture of dilated cerebral veins as a result of retrograde drainage.

When DFCS is clinically suspected, the patient must be carefully examined for confirmatory signs. In the presence of an eye with engorged vessels, conjunctival erythema or proptosis is mandatory to auscultate the skull and facial bones searching for murmurs. Usually the affected eye is ipsilateral to the fistula, however there are cases of bilateral symptoms due to the commitment of both cavernous sinuses because communication between them through intercavernous sinuses.

\section{Imaging findings}


The imaging method for initial assessment of the DFCS is the magnetic resonance imaging (MRI). The findings include: 1) increased volume of the cavernous sinus; 2) loss of the interface between the cavernous sinus and the intracavernous portion of the ICA, 3) dilation of the superior ophthalmic vein $(17,18)$.

Digital subtraction angiography (DSA) is the method of choice to determine adequately the precise angioarchitecture of the injury and its drainage. This data is of vital importance in future decision making. Therefore, the angiographic evaluation must provide specific information regarding arterial tributaries, the precise site of shunt and the venous drainage pattern. In many cases this analysis can only be complete during the therapeutic phase. For this, it is recommended the angiographical evaluation in two phases: 1) diagnostic catheterization and 2) supraselective catheterization, which can be performed during treatment of the injury.

Some authors have emphasized the importance of non-invasive alternatives modalities such as helical CT-angiography (angio-CT) and magnetic resonance angiography (MRA), which is supposed to characterize the injury angioarchitecture (18). However, even with the visualization of afferent vessels and draining veins, DSA only guides in analyzing how the different compartments involved are interrelated, and helps the understanding of the hemodynamics of the lesion, enabling better therapeutic approach. Thus, the DSA still remains the gold standard for assessing DFCS.
Barrow et al (19) proposed an angiographic classification for CCF, revalidated by Debrun et al (7), and widely used by diverse authors, see Table 1. In the review of literature persists the trending of the predominance of the CCF type D over type $\mathrm{C}$, being truly extraordinary the type $\mathrm{B}$.

\section{TABLE 1}

Barrow classification of DFCS

\begin{tabular}{|c|c|c|}
\hline Type & Fistulous vessels & Characteristics \\
\hline $\mathbf{A}$ & $\begin{array}{l}\text { Carotid artery to cavernous } \\
\text { sinus }\end{array}$ & $\begin{array}{l}\text { Direct, high } \\
\text { flow, the most } \\
\text { common }\end{array}$ \\
\hline B & $\begin{array}{l}\text { Dural ICA branches to } \\
\text { Cavernous sinus: } \\
\text {-Meningohypophyseal } \\
\text { trunk }(66 \%) \\
\text {-Inferolateral trunk }(30 \%)\end{array}$ & $\begin{array}{l}\text { Indirect, low } \\
\text { flow }\end{array}$ \\
\hline $\mathrm{C}$ & $\begin{array}{l}\text { ECA branches to } \\
\text { Cavernous sinus: } \\
\text {-Internal maxillary }(67 \%) \\
\text {-Middle meningeal }(31 \%) \\
\text {-Ascending pharyngeal } \\
(24 \%)\end{array}$ & $\begin{array}{l}\text { Indirect, low } \\
\text { flow }\end{array}$ \\
\hline D & $\begin{array}{l}\text { Both ICA and ECA } \\
\text { branches }\end{array}$ & $\begin{array}{l}\text { Indirect, the } \\
\text { most common } \\
\text { of low flow }\end{array}$ \\
\hline
\end{tabular}

\section{Why and when to treat DFCS?}

From all dural fistulas, about $10 \%$ to $60 \%$ can present spontaneous resolution, and 25 to $50 \%$ are to the cavernous sinus, therefore have a much more benign course than direct CCF with a natural history that can lead to spontaneous healing. $(10,15,16,19-22)$ The cure occurring shortly after performing diagnostic angiography is not rare. Many patients experience a period of worsening of symptoms, particularly ophthalmics, during the spontaneous healing process. $(12,23)$ For 
DOI: 10.2478/romneu-2014-0015

this reason the decision on the management of the DFCS is controversial. Keltner, et al (10) treated by endovascular approach only 1 of the 10 cases reported, while 7 were offered only ophthalmologic management with treatment for glaucoma, reporting good control, therefore conclude that these cases should not be subjected to definitive treatment.

Currently are considered as indications for the management of DFCS: 1) rapidly progressive deterioration of visual function, 2) angiographic evidence of abnormal cortical venous drainage, 3 ) the hypoxic consequences in retina and optic nerve, and 4) ischemic keratitis $(5,11,12,20)$. Among the mechanisms involved in the worsening of dural fistulas are: 1) stenosis or thrombosis of the outflow, 2) increasing of the arterial blood flow, and 3) the emergence of a new fistula or enlargement of preexisting shunt $(21,24)$.

In the days before the advent of Neurological Endovascular Therapy, traditional surgery for the management of this condition was accompanied by a very high risk of thromboembolic events, almost always accompanied by cerebral ischemic disease and/or blindness (11). Currently the endovascular therapy is considered as the treatment of choice for all types of CCF for the following reasons: 1 ) is performed under local anesthesia with the possibility of ongoing clinical evaluation of the patient for early detection of any complication, 2) is a low risk approach, 3) less time consumption during the procedure, 4) reaches surgically inaccessible sites, 5) more likely to conserve the ICA blood flow, 6) fast recovery of the patient, and 7) there is always the possibility to repeat the procedure in case of initial failure or recurrence of the fistula $(3-5,7,9,11,12,20$, 25)

\section{Approach route}

The DFCS are arteriovenous or arteriovenous shunts, in these cases it is determined that occlusion of the venous portion is the treatment of choice (26-28) for this purpose transvenous route is usually the best access method for insertion and release of embolic material, with current predominant use of detachable coils. Different routes have been described and used to reach the cavernous sinus, such as through lower petrosal sinus (contralateral or ipsilateral), basilar plexus, circular or intercavernous sinus, through the facial vein, the angular and superior ophthalmic veins or through the pterygoid plexus $(5,11,20,24,25,29-34)$.

In a large retrospective study, Mayers et al (5), summarizes 15 years of experience in the management of 135 DFCS patients treated transvenously, coils were used in $87 \%$ of cases, pieces of suture material in $13 \%$ and only in 3\% of patients was used liquid adhesive material. They reported good long-term results in 97\% of cases. Cheng et al (25) reported the cases of 27 patients treated transvenously with GDC and fibered coils, where only one case was necessary to combine with the arterial line for administration of PAP; in these same study, $89 \%$ of the cases experimented angiographic cure (25).

Retrospectively, Klish et al, reported 11 cases of DFCS embolized by transvenous approach with coils, reaching a frequency of anatomical cure of $63 \%$, however, they refer 
that all patients, including those who did not achieve such healing, showed improvement in their symptoms (20). Reported complications of the transvenous approach with occlusion of the cavernous sinus, the lesion of the vein access, the immediate and rapid increase of the ophthalmologic symptomatology and the injury of any of the oculomotor nerves caused either by over-packing of coils or induced thrombotic process itself within the sinus (10, 25). Furthermore, it has been determined in the case of dural fistulas that sinus therapeutic occlusion with coils, and the subsequent thrombosis can activate angiogenic factors within the adjacent dural walls $(22,32,35-37)$.

In cases where it is not possible to exploit adequately the venous approach, the arterial approach can be useful $(11,12)$. CA is the material of choice in the arterial approach because allows better control of time and degree of polymerization modifying its dilution with the lipid contrast dye without starting with a total sacrifice of the circulation of the cavernous sinus, situation that makes it a more controllable material than PAP.

Some authors not use the transvenous approach just for the likelihood of these complications plus it is expensive for the number of coils typically required to occlude the cavernous sinus, fact that in economic stringency environments becomes a major limiting factor in the decision making.

One limitation of the arterial approach is the partial treatment of the fistula, particularly in type $\mathrm{D}$ cases, in which only were treated the fistulous pedicles of a single axis. This, in theory, perpetuates the fistula and may even increase the flow in other components, but our percentage of success and immediate and long-term cure is high. We think this is because the decision to embolize the pedicles of greater flow, and allow the passage of embolic material to the malformation own nest which could induce a progressive thrombosis of the compromised segments of the cavernous sinus, this thrombosis is seen further promoted by combination with manual compression maneuver of the carotid artery. Hence can be avoided the nerve damage of oculomotor nerves or ophthalmologic deterioration that can be observed with the venous approach, and is a far less expensive method.

Satomi et al (24), have shown that partial treatment of DFCS, to what they have called palliative treatment, induces progressive changes in the pattern of venous drainage of the cavernous sinus with a trend towards very benign evolution with minimal ophthalmological commitment and almost no dilated cortical veins.

Another advantage observed with the arterial approach is the use of catheters guided by the flow, so far as possible avoids the use of microguides, which are to blame for vascular injury in case of venous approach. Among the complications of trans-arterial route, Viñuela et al (12) reported migration of the CA into distal branches of the middle cerebral artery, fortunately without much clinical implication, in addition to the transient increase in retroocular pain of one patient.

\section{Embolization material}

Viñuela et al (12) concluded that the most suitable materials for embolization of the DFCS are CA and PAP. The use of CA is 
DOI: 10.2478/romneu-2014-0015

currently widespread in the management of arteriovenous malformations (AVM), the opposite situation occurs in DFCS with few reports or small series. CA was first used as management of direct CCF in a case treated by Bank et al (38) and in three cases managed by Kerber et al (39) reported in 1978 and 1979, respectively in which is highlighted the conservation of the carotid flow which was established in a situation really encouraging, in a time when most endovascular and surgical techniques aimed to blood flow occlusion of the ICA.

It is noteworthy that the experience of the last authors was when acrylic was not approved by the FDA for use in humans in northamerica. So was criticized and considered dangerous, and that the three cases described by Kerber et al (39) presented some type of deficit arising from the migration of the substance or by the application of the microcatheter or the non-detachable ballon technique used to administrate the substance, although the deficit was transient and the evolution of the patients was good in the short and medium term. Some authors like Pierot et al (40), Luo et al (3) and Wang et al (41) reported their successful experience with $\mathrm{CA}$ in management of direct CCF of traumatic origin, partially treated or recurrent. Berenstein et al (9) were first to use CA in the management of DFCS, which in turn was caused by trauma (9).

From 10 cases described by Keltner et al (10), only one was treated by endovascular technique with glue, precisely their single case secondary to trauma. Viñuela et al (12) described a series of 16 spontaneous DFCS, of which four were treated with $\mathrm{AC}, 1$ with $\mathrm{CA}$ and surgery, 1 with $\mathrm{CA}$ and particles, and 3 with only particles. From all cases only one was identified as "inadequate" healing. These authors conclude that the CA and the particles must be considered as the treatment of choice in the DFCS because allow superselective and more distal tributary vessels occlusion near the nest of the arterio-venous fistula, they consider that this may be sufficient to promote the cavernous sinus thrombosis with consequent total occlusion of the lesion.

Debrun et al (7) reported 132 cases of CCF, from which 32 were DFCS, of which 13 cases were treated only with $\mathrm{CA}$, and the remaining with PAP or a mixture of both. Cure was obtained in 16 patients, whereas in the patients without early cure, some progressively improved, while others were lost to follow. It is necessary to emphasize that in this study the majority of indirect fistulas were type D (28 of 32 cases) and the authors conclude that they are the most difficult to treat because of the increased number of branches involved, which came from both ACE and ACI, hence adequate obliteration was more difficult to achieve, especially when considering that that occlusion of only ACE flow can result in increased participation of the meningeal branches of the ICA with much more difficult management in later stages (7).

Type D fistulas are more laborious, also require more mental exercise and can be disappointing for the endovascular specialist. For this reason some authors have considered to radiosurgery as a treatment option in selected cases, being combined with embolization or even with no pretreatment 
(42-46), however, more experience is needed with long-term outcomes to determine its efficacy and safety.

\section{Conclusions}

DFCS stills being an uncommon cerebrovascular condition, with good outcomes from endovascular treatment. Currently the endovascular therapy is considered as the treatment of choice for all types of CCF, because good outcomes, and because traditional surgery is accompanied by a very high risk of thromboembolic events, almost always accompanied by cerebral ischemic disease and/or blindness.

\section{Abbreviations:}

AVM: Arterio-venous malformation

CA: Cyanoacrylate.

CCF: Carotid-cavernous fistula.

DFCS: Dural fistula into the cavernous sinus

DSA: Digital substraction angiography

ECA: External carotid artery.

GDC: Guglielmi detachable coils.

ICA: Internal carotid artery.

MRI: Magnetic resonance imaging

PAP: Polyvinyl-alcohol particles.

\section{Correspondence:}

Dr. Luis Rafael Moscote-Salazar, Universidad de Cartagena, Cartagena de Indias, Colombia e-mail: mineurocirujano@aol.com

\section{References}

1. Kähärä Veikko J, Seppänen S, Kuurne T, Laasonen EM. Endovascular treatment of carotid-cavernous fistulae. Acta Neurol Scand [Internet]. 1998 Oct [cited 2013 May 25];98(4):254-8. Available from: http://www.ncbi.nlm.nih.gov/pubmed/9808275
2. Lewis AI, Tomsick TA, Tew JM. Management of 100 consecutive direct carotid-cavernous fistulas: results of treatment with detachable balloons. Neurosurgery [Internet]. 1995 Feb [cited 2013 May 25];36(2):239-44; discussion 244-5. Available from: http://www.ncbi.nlm.nih.gov/pubmed/7731502 3. Luo C-B, Teng MM-H, Yen DH-T, Chang F-C, Lirng J-F, Chang C-Y. Endovascular embolization of recurrent traumatic carotid-cavernous fistulas managed previously with detachable balloons. J Trauma [Internet]. 2004 Jun [cited 2013 May 25];56(6):1214-20. Available from: http://www.ncbi.nlm.nih.gov/pubmed/15211128 4. Luo C-B, Teng MM-H, Chang F-C, Lirng J-F, Chang $\mathrm{C}-\mathrm{Y}$. Endovascular management of the traumatic cerebral aneurysms associated with traumatic carotid cavernous fistulas. AJNR Am J Neuroradiol [Internet]. 2004 Mar [cited 2013 May 25];25(3):501-5. Available from: http://www.ncbi.nlm.nih.gov/pubmed/15037481

5. Meyers PM, Halbach V V, Dowd CF, Lempert TE, Malek AM, Phatouros CC, et al. Dural carotid cavernous fistula: definitive endovascular management and longterm follow-up. Am J Ophthalmol [Internet]. 2002 Jul [cited 2013 Apr 24];134(1):85-92. Available from: http://www.ncbi.nlm.nih.gov/pubmed/12095813

6. Jacobson BE, Nesbit GM, Ahuja A, Barnwell SL. Traumatic indirect carotid-cavernous fistula: report of two cases. Neurosurgery [Internet]. 1996 Dec [cited 2013 Apr 24];39(6):1235-7; discussion 1237-8. Available from: http://www.ncbi.nlm.nih.gov/pubmed/8938780

7. Debrun GM, Viñuela F, Fox AJ, Davis KR, Ahn HS. Indications for treatment and classification of 132 carotid-cavernous fistulas. Neurosurgery [Internet]. 1988 Feb [cited 2013 Apr 24];22(2):285-9. Available from: http://www.ncbi.nlm.nih.gov/pubmed/3352876

8. Alvis-Miranda H, Castellar-Leones S, Alcala-Cerra G, Moscote-Salazar L. Cerebral sinus venous thrombosis. J Neurosci Rural Pr [Internet]. 2013 [cited 2013 Oct 25];4(4):427. Available from:

http://www.ruralneuropractice.com/text.asp?2013/4/4/4 27/120236

9. Berenstein A, Scott J, Choi IS, Persky M. Percutaneous embolization of arteriovenous fistulas of the external carotid artery. AJNR Am J Neuroradiol [Internet]. 1986 [cited 2013 Apr 24];7(5):937-42. Available from: http://www.ncbi.nlm.nih.gov/pubmed/3096119 10. Keltner JL, Satterfield D, Dublin AB, Lee BC. Dural and carotid cavernous sinus fistulas. Diagnosis, 
DOI: 10.2478/romneu-2014-0015

management, and complications. Ophthalmology [Internet]. 1987 Dec [cited 2013 Apr 24];94(12):1585600. Available from:

http://www.ncbi.nlm.nih.gov/pubmed/3323984

11. Higashida RT, Halbach V V, Tsai FY, Norman D, Pribram HF, Mehringer $\mathrm{CM}$, et al. Interventional neurovascular treatment of traumatic carotid and vertebral artery lesions: results in 234 cases. AJR Am J Roentgenol [Internet]. 1989 Sep [cited 2013 Apr 24];153(3):577-82. Available from:

http://www.ncbi.nlm.nih.gov/pubmed/2763958

12. Viñuela F, Fox AJ, Debrun GM, Peerless SJ, Drake CG. Spontaneous carotid-cavernous fistulas: clinical, radiological, and therapeutic considerations. Experience with 20 cases. J Neurosurg [Internet]. 1984 May [cited 2013 Apr 24];60(5):976-84. Available from:

http://www.ncbi.nlm.nih.gov/pubmed/6716167

13. Kiyosue H, Hori Y, Okahara M, Tanoue S, Sagara Y, Matsumoto S, et al. Treatment of intracranial dural arteriovenous fistulas: current strategies based on location and hemodynamics, and alternative techniques of transcatheter embolization. Radiographics [Internet]. 2004 [cited 2013 May 25];24(6):1637-53. Available from: http://www.ncbi.nlm.nih.gov/pubmed/15537974

14. Suh DC, Lee JH, Kim SJ, Chung SJ, Choi CG, Kim HJ, et al. New concept in cavernous sinus dural arteriovenous fistula: correlation with presenting symptom and venous drainage patterns. Stroke [Internet]. 2005 Jun [cited 2013 May 25];36(6):1134-9. Available from:

http://www.ncbi.nlm.nih.gov/pubmed/15890994

15. Lasjaunias P, Chiu M, ter Brugge K, Tolia A, Hurth M, Bernstein M. Neurological manifestations of intracranial dural arteriovenous malformations. J Neurosurg [Internet]. 1986 May [cited 2013 Apr 24];64(5):724-30. Available from:

http://www.ncbi.nlm.nih.gov/pubmed/3701421

16. Palestine AG, Younge BR, Piepgras DG. Visual prognosis in carotid-cavernous fistula. Arch Ophthalmol [Internet]. 1981 Sep [cited 2013 Apr 24];99(9):1600-3. Available from:

http://www.ncbi.nlm.nih.gov/pubmed/7283811

17. Kwon BJ, Han MH, Kang H-S, Chang K-H. MR imaging findings of intracranial dural arteriovenous fistulas: relations with venous drainage patterns. AJNR Am J Neuroradiol [Internet]. 2005 [cited 2013 May 25];26(10):2500-7. Available from:

http://www.ncbi.nlm.nih.gov/pubmed/16286391
18. Tsai Y-F, Chen L-K, Su C-T, Lu T-N, Wu C-C, Kuo C-J. Utility of source images of three-dimensional timeof-flight magnetic resonance angiography in the diagnosis of indirect carotid-cavernous sinus fistulas. J Neuroophthalmol [Internet]. 2004 Dec [cited 2013 May 25];24(4):285-9. Available from:

http://www.ncbi.nlm.nih.gov/pubmed/15662241

19. Barrow DL, Spector RH, Braun IF, Landman JA, Tindall SC, Tindall GT. Classification and treatment of spontaneous carotid-cavernous sinus fistulas. J Neurosurg [Internet]. 1985 Feb [cited 2013 Apr 24];62(2):248-56. Available from:

http://www.ncbi.nlm.nih.gov/pubmed/3968564

20. Klisch J, Huppertz HJ, Spetzger U, Hetzel A, Seeger W, Schumacher M. Transvenous treatment of carotid cavernous and dural arteriovenous fistulae: results for 31 patients and review of the literature. Neurosurgery [Internet]. 2003 Oct [cited 2013 Apr 24];53(4):836-56; discussion 856-7. Available from:

http://www.ncbi.nlm.nih.gov/pubmed/14519216

21. Satomi J, Satoh K, Matsubara S, Nakajima N, Nagahiro S. Angiographic changes in venous drainage of cavernous sinus dural arteriovenous fistulae after palliative transarterial embolization or observational management: a proposed stage classification. Neurosurgery [Internet]. $2005 \mathrm{Mar}$ [cited $2013 \mathrm{Apr}$ 24];56(3):494-502; discussion 494-502. Available from: http://www.ncbi.nlm.nih.gov/pubmed/15730574

22. Makiuchi T, Takasaki K, Yamagami M, Oda H, Todoroki K, Atsuchi M, et al. A case of sigmoid sinus dural arteriovenous fistula after treated cavernous dural arteriovenous fistula. Interv Neuroradiol [Internet]. 1998 Nov 30 [cited 2013 Apr 24];4 Suppl 1:219-22. Available from: http://www.ncbi.nlm.nih.gov/pubmed/20673478 23. Sergott RC, Grossman RI, Savino PJ, Bosley TM, Schatz NJ. The syndrome of paradoxical worsening of dural-cavernous sinus arteriovenous malformations. Ophthalmology [Internet]. 1987 Mar [cited 2013 Apr 24];94(3):205-12. Available from:

http://www.ncbi.nlm.nih.gov/pubmed/3587894

24. Satomi J, van Dijk JMC, Terbrugge KG, Willinsky RA, Wallace MC. Benign cranial dural arteriovenous fistulas: outcome of conservative management based on the natural history of the lesion. J Neurosurg [Internet]. 2002 Oct [cited 2013 Apr 24];97(4):767-70. Available from: http://www.ncbi.nlm.nih.gov/pubmed/12405361 
25. Cheng K-M, Chan C-M, Cheung Y-L. Transvenous embolisation of dural carotid-cavernous fistulas by multiple venous routes: a series of 27 cases. Acta Neurochir [Internet]. 2003 Jan [cited 2013 Apr 24];145(1):17-29. Available from:

http://www.ncbi.nlm.nih.gov/pubmed/12545258

26. Houdart E, Saint-Maurice J-P, Chapot R, Ditchfield A, Blanquet A, Lot $G$, et al. Transcranial approach for venous embolization of dural arteriovenous fistulas. J Neurosurg [Internet]. 2002 Aug [cited 2013 May 25];97(2):280-6. Available from:

http://www.ncbi.nlm.nih.gov/pubmed/12186454

27. Urtasun F, Biondi A, Casaco A, Houdart E, Caputo N, Aymard A, et al. Cerebral dural arteriovenous fistulas: percutaneous transvenous embolization. Radiology [Internet]. 1996 Apr [cited 2013 May 5];199(1):209-17. Available from:

http://www.ncbi.nlm.nih.gov/pubmed/8633147

28. Cognard C, Gobin YP, Pierot L, Bailly AL, Houdart E, Casasco A, et al. Cerebral dural arteriovenous fistulas: clinical and angiographic correlation with a revised classification of venous drainage. Radiology [Internet]. 1995 Mar [cited 2013 May 25];194(3):671-80. Available from: http://www.ncbi.nlm.nih.gov/pubmed/7862961 29. Hosobuchi Y. Electrothrombosis of carotidcavernous fistula. J Neurosurg [Internet]. 1975 Jan [cited 2013 Apr 24];42(1):76-85. Available from: http://www.ncbi.nlm.nih.gov/pubmed/1110393

30. Mullan S. Treatment of carotid-cavernous fistulas by cavernous sinus occlusion. J Neurosurg [Internet]. 1979 Feb [cited 2013 Apr 24];50(2):131-44. Available from: http://www.ncbi.nlm.nih.gov/pubmed/430123

31. Teng MM, Guo WY, Huang CI, Wu CC, Chang T. Occlusion of arteriovenous malformations of the cavernous sinus via the superior ophthalmic vein. AJNR Am J Neuroradiol [Internet]. 1988 [cited 2013 Apr 24];9(3):539-46. Available from:

http://www.ncbi.nlm.nih.gov/pubmed/3132828

32. Yamashita K, Taki W, Nishi S, Sadato A, Nakahara I, Kikuchi $\mathrm{H}$, et al. Transvenous embolization of dural caroticocavernous fistulae: technical considerations. Neuroradiology [Internet]. 1993 Jan [cited 2013 Apr 24];35(6):475-9. Available from:

http://www.ncbi.nlm.nih.gov/pubmed/8377926

33. Berkmen T, Troffkin NA, Wakhloo AK. Transvenous sonographically guided percutaneous access for treatment of an indirect carotid cavernous fistula. AJNR
Am J Neuroradiol [Internet]. 2003 Sep [cited 2013 Apr 24];24(8):1548-51. Available from: http://www.ncbi.nlm.nih.gov/pubmed/13679268 34. Bellon RJ, Liu AY, Adler JR, Norbash AM. Percutaneous transfemoral embolization of an indirect carotid-cavernous fistula with cortical venous access to the cavernous sinus. Case report. J Neurosurg [Internet]. 1999 May [cited 2013 Apr 24];90(5):959-63. Available from:

http://www.ncbi.nlm.nih.gov/pubmed/10223466

35. Kubota Y, Ueda T, Kaku Y, Sakai N. Development of a dural arteriovenous fistula around the jugular valve after transvenous embolization of cavernous dural arteriovenous fistula. Surg Neurol [Internet]. 1999 Feb [cited 2013 Apr 24];51(2):174-6. Available from: http://www.ncbi.nlm.nih.gov/pubmed/10029423

36. Kurl S, Vanninen R, Saari T, Hernesniemi J. Development of right transverse sinus dural arteriovenous malformation after embolisation of a similar lesion on the left. Neuroradiology [Internet]. 1996 May [cited 2013 Apr 24];38(4):386-8. Available from: http://www.ncbi.nlm.nih.gov/pubmed/8738104

37. Nakagawa H, Kubo S, Nakajima Y, Izumoto S, Fujita T. Shifting of dural arteriovenous malformation from the cavernous sinus to the sigmoid sinus to the transverse sinus after transvenous embolization. A case of left spontaneous carotid-cavernous sinus fistula. Surg Neurol [Internet]. 1992 Jan [cited 2013 Apr 24];37(1):30-8. Available from:

http://www.ncbi.nlm.nih.gov/pubmed/1727080 38. Bank WO, Kerber CW, Drayer BP, Troost BT, Maroon JC. Carotid cavernous fistula: endarterial cyanoacrylate occlusion with preservation of carotid flow. J Neuroradiol [Internet]. 1978 Dec [cited 2013 May 25];5(4):279-85. Available from:

http://www.ncbi.nlm.nih.gov/pubmed/755100 39. Kerber CW, Bank WO, Cromwell LD. Cyanoacrylate occlusion of carotid-cavernous fistula with preservation of carotid artery flow. Neurosurgery [Internet]. 1979 Mar [cited 2013 May 25];4(3):210-5. Available from: http://www.ncbi.nlm.nih.gov/pubmed/460551 40. Pierot L, Moret J, Boulin A, Castaings L. Endovascular treatment of post-traumatic complex carotid-cavernous fistulas, using the arterial approach. J Neuroradiol [Internet]. 1992 Jan [cited 2013 May 25];19(2):79-87. Available from: http://www.ncbi.nlm.nih.gov/pubmed/1629778 
DOI: 10.2478/romneu-2014-0015

41. Wang D, Ling F, Li M, Zhang H, Miu Z, Song Q, et al. [Refractory carotid-cavernous fistula: causes and countermeasures]. Zhonghua Wai Ke Za Zhi [Internet]. 1999 Dec [cited 2013 May 25];37(12):754-6. Available from: http://www.ncbi.nlm.nih.gov/pubmed/11829946 42. Hasuo K, Mizushima A, Matsumoto S, Uchino A, Uehara S, Miyoshi M, et al. Type D dural carotidcavernous fistula. Results of combined treatment with irradiation and particulate embolization. Acta Radiol [Internet]. 1996 May [cited 2013 May 25];37(3 Pt 1):2948. Available from:

http://www.ncbi.nlm.nih.gov/pubmed/8845256

43. Bitoh S, Hasegawa H, Fujiwara $M$, Nakao $K$. Irradiation of spontaneous carotid-cavernous fistulas. Surg Neurol [Internet]. 1982 Apr [cited 2013 May 25];17(4):282-6. Available from:

http://www.ncbi.nlm.nih.gov/pubmed/7079953
44. Hidaka $\mathrm{H}$, Terashima $\mathrm{H}$, Tsukamoto $\mathrm{Y}$, Nakata $\mathrm{H}$, Matsuoka S. Radiotherapy of dural arteriovenous malformation in the cavernous sinus. Radiat Med [Internet]. 1989 [cited 2013 May 25];7(3):160-4. Available from: http://www.ncbi.nlm.nih.gov/pubmed/2587806 45. Pierot L, Poisson M, Jason M, Pontvert D, Chiras J. Treatment of type D dural carotid-cavernous fistula by embolization followed by irradiation. Neuroradiology [Internet]. 1992 Jan [cited 2013 May 25];34(1):77-80. Available from:

http://www.ncbi.nlm.nih.gov/pubmed/1553043 46. Guo WY, Pan DH, Wu HM, Chung WY, Shiau CY, Wang LW, et al. Radiosurgery as a treatment alternative for dural arteriovenous fistulas of the cavernous sinus. AJNR Am J Neuroradiol [Internet]. 1998 [cited 2013 May 25];19(6):1081-7. Available from: http://www.ncbi.nlm.nih.gov/pubmed/9672015. 